\title{
Magnesium Supplementation Alleviates Premenstrual Symptoms of Fluid Retention
}

\author{
ANN F. WALKER, Ph.D., ${ }^{1}$ MIRIAM C. DE SOUZA, Ph.D., ${ }^{1}$ MICHAEL F. VICKERS, M.Phil., ${ }^{2}$ \\ SAVITRI ABEYASEKERA, Ph.D., ${ }^{3}$ MARILYN L. COLLINS, B.A., ${ }^{3}$ \\ and LUZIA A. TRINCA, Ph.D. ${ }^{4}$
}

\begin{abstract}
We investigated the effect of a daily supplement of $200 \mathrm{mg}$ of magnesium (as $\mathrm{MgO}$ ) for two menstrual cycles on the severity of premenstrual symptoms in a randomized, double-blind, placebo-controlled, crossover study. A daily supplement of $200 \mathrm{mg}$ of $\mathbf{M g}$ (as $\mathrm{MgO}$ ) or placebo was administered for two menstrual cycles to each volunteer, who kept a daily record of her symptoms, using a 4-point scale in a menstrual diary of 22 items. Symptoms were grouped into six categories: PMS-A (anxiety), PMS-C (craving), PMS-D (depression), PMS-H (hydration), PMS-O (other), and PMS-T (total overall symptoms). Urinary Mg output/24 hours was estimated from spot samples using the $\mathrm{Mg} / \mathrm{creatinine}$ ratio. Analysis of variance for 38 women showed no effect of $\mathrm{Mg}$ supplementation compared with placebo in any category in the first month of supplementation. In the second month there was a greater reduction $(p=0.009)$ of symptoms of PMS-H (weight gain, swelling of extremities, breast tenderness, abdominal bloating) with $\mathrm{Mg}$ supplementation compared with placebo. Compliance to supplementation was confirmed by the greater mean estimated 24-hour urinary output of $\mathrm{Mg}(p=0.013)$ during $\mathrm{Mg}$ supplementation (100.8 $\mathrm{mg}$ ) compared with placebo $(74.1 \mathrm{mg})$. A daily supplement of $200 \mathrm{mg}$ of $\mathrm{Mg}$ (as $\mathrm{MgO}$ ) reduced mild premenstrual symptoms of fluid retention in the second cycle of administration.
\end{abstract}

\section{INTRODUCTION}

T HE PREMENSTRUAL SYNDROME (PMS) has been described by Reid and Yen as "the cyclic recurrence in the luteal phase of the menstrual cycle of a combination of distressing physical, psychological, and/or behavioral changes of sufficient severity to result in deterioration of interpersonal relationships and/or interference with normal activities." 1 The lack of consensus among gynecologists and researchers in defining PMS is due to the absence of measurable signs and the wide range of psychologic and somatic symptoms described for the condition. Abraham, ${ }^{2}$ who has researched the dietary etiology of PMS for over two decades, has described four PMS categories: A (anxiety related), C (craving related), D (depression related), and $\mathrm{H}$ (hydration related). Although not universally accepted, this classification has found favor among several researchers. ${ }^{3}$

\footnotetext{
${ }^{1}$ Hugh Sinclair Unit of Human Nutrition, Department of Food Science and Technology, The University of Reading, Reading, U.K.

${ }^{2}$ Department of Clinical Biochemistry, Royal Berkshire Hospital, Reading, U.K.

${ }^{3}$ Department of Applied Statistics, The University of Reading, Reading, U.K.

${ }^{4}$ Departamento de Bioestatistica, Instituto de Biociencias, Universidade Estadual Paulista, Botucatu, Sao Paulo, Brazil.
} 
The prevalence of PMS among the female population varies greatly, according to reports. In London, Dalton ${ }^{4}$ found that between $20 \%$ and $30 \%$ of women could be classified as sufferers, and others report even higher prevalence. For example, Johnson et al. ${ }^{5}$ reported PMS in $87 \%$ of 996 nursing school graduates, whereas the incidence of PMS in 1395 gynecologic patients aged 13-54 years was $50 \%$ in another study. ${ }^{6}$ These inconsistencies may partly reflect the lack of a clear definition of PMS as well as differences in study methodology, although they also depend on the group studied. Particular group bias includes age (peak incidence for women in their 30s has been reported $^{6}$ ), parity, race, culture, occupation, lifestyle stresses, ${ }^{7}$ and diet.

If subclasses of PMS exist, as suggested by Abraham, ${ }^{2}$ there is the possibility of several distinct etiologies for the condition. Indeed, various hypotheses have been promulgated, involving interaction among ovarian steroid hormones, endogenous opioid peptide release in the brain, balance of central neurotransmitters, formation of inflammatory eicosanoids, and changes in peripheral autonomic and endocrine function. However, despite various investigations, the pathophysiologic basis of PMS still remains obscure, particularly in the absence of animal models for the condition. Although the ovarian hormone imbalance hypothesis finds most favor and progesterone administration in the latter half of the cycle continues to be first-line treatment by general practitioners, ${ }^{8}$ there are still many uncertainties about its validity. ${ }^{9}$

Various reports, many of a preliminary nature or based on clinical experience, suggest that women suffering from PMS consume more refined carbohydrate and dairy products and less vitamin B-complex, iron, zinc, and magnesium $(\mathrm{Mg})$ than nonsufferers. ${ }^{10}$ Of all the dietary factors suggested, magnesium is the best researched. $\mathrm{Mg}$ is low in the diets of a substantial proportion of women consuming western-type diets, as has been demonstrated in many dietary surveys. For example, the mean intake of $\mathrm{Mg}$ of over 1000 British women was $237 \mathrm{mg} /$ day $^{11}$ corresponding to $88 \%$ of the Reference Nutrient Intake (RNI). ${ }^{12}$

The role of $\mathrm{Mg}$ deficiency in the etiology of PMS was first proposed by Abraham, ${ }^{2}$ who reasoned that in $\mathrm{Mg}$ deficiency, enhanced intake of $\mathrm{Mg}$ would have a sedative effect on neuromuscular excitability and restore cell membrane electrolyte imbalance to normal, which would have a diverse subtle physiologic effect. As $\mathrm{Mg}$ is found predominantly inside the cell, intracellular $\mathrm{Mg}$ concentration is a better reflection of body status than blood measurements. Thus, although plasma $\mathrm{Mg}$ levels have been reported to be unrelated to PMS,13 poor erythrocyte $\mathrm{Mg}$ status is the most consistent physiologic abnormality found among PMS sufferers compared with normal controls. ${ }^{14-16}$

Apart from the role that $\mathrm{Mg}$ plays in maintenance of the electrical potential of the cell membrane, including neuromuscular function, it is an essential cofactor for enzymes that require ATP. It is also involved in the synthesis and replication of RNA and DNA. ${ }^{17}$ Hence, $\mathrm{Mg}$ deficiency is likely to affect the normal functioning of many body systems, including liver function. ${ }^{18}$ Of particular relevance to the multifaceted presentations of PMS is the role of $\mathrm{Mg}$ in stimulating the synthesis of nitric oxide (NO) ${ }^{19}$ and eicosanoids ${ }^{20}$ involved in balancing the inflammatory response, as well as its role in neurotransmitter activity. ${ }^{21}$

The only controlled study carried out on $\mathrm{Mg}$ supplementation alone for its effects on PMS was that of Facchinetti et al. ${ }^{3}$ These authors found that $360 \mathrm{mg}$ of $\mathrm{Mg}$ per day given in three divided doses in the luteal phase of the cycle alleviated anxiety-related PMS (mood changes), compared with placebo, when administered over four menstrual cycles. The same authors found that a similar regimen was effective in treating premenstrual migraine headaches. ${ }^{22}$

The present study was inspired by the work of Facchinetti et al. ${ }^{3}$ However, our protocol differed from that used by the Italian workers in that (1) the supplement (or placebo) was administered throughout the menstrual cycle and not just during the latter half of it, (2) the amount of $\mathrm{Mg}$ administered per day was lower $(200 \mathrm{mg} /$ day rather than $360 \mathrm{mg} /$ day), and (3) the $\mathrm{Mg}$ supplement was given in one single daily dose rather than in three divided doses throughout the day. The low dose of $\mathrm{Mg}$ was chosen to represent a true supplement to dietary intake rather than being a pharmacologic dose.

\section{MATERIALS AND METHODS}

\section{Ethical permission}

The protocol for the study was scrutinized and allowed by The University of Reading Ethics and Research Committee. 


\section{Volunteers}

Women suffering from premenstrual symptoms were recruited from among the student and employee population of The University of Reading by means of poster advertisements placed throughout the university. A signed consent from each volunteer and agreement from the volunteer's general practitioner were required before entry into the study.

\section{Experimental design}

The duration of dietary supplementation was four menstrual cycles. The volunteers were divided randomly into two groups. For the first two cycles, starting at day 1 of the menstrual cycle (the first day of bleeding), members of one group each received a single $\mathrm{Mg}$ tablet per day, and each member of the other group received one placebo tablet per day. At the start of the third menstrual cycle, the daily supplement was crossed over for each volunteer, so that those taking $\mathrm{Mg}$ were requested to take placebo, and vice versa, and to continue to do so to the end of the fourth cycle.

The formulation of the Mg supplement was 200 mg magnesium oxide (MgO) (heavy precipitate) with $100 \mathrm{mg}$ of mixed amino acids (Lamberts Healthcare Ltd., Tunbridge Wells, Kent, U.K.). The placebo tablets contained microcrystalline cellulose. All tablets were supplied in coded, sealed, plastic containers sufficient for 1 month for one volunteer. Each month's supply of tablets were sent by post or delivered by hand with instructions for use and a blank menstrual diary to be filled in from the start of the next cycle.

\section{Premenstrual symptom records}

Before the study commenced, volunteers were asked to complete a Menstrual Health Questionnaire (MHQ), modified from Warner and Bancroft. ${ }^{7}$ This was divided into two parts involving (1) questions on the volunteer's general menstrual health, age, parity, oral contraceptive (OC) use, and premenstrual symptom experience and (2) a retrospective assessment of the severity of symptoms suffered during the last cycle, using a 27-symptom classification, each to be assessed on a 5-point scale (1, very mild; 2 , mild; 3, moderate; 4 , severe; 5 , very severe) for the premenstrual and postmenstrual phases of the cycle. Only those subjects showing at least a $30 \%$ drop in total symptoms between premen- strual and postmenstrual scores were entered into the study.

Once supplementation had started, volunteers were asked to keep a daily record of their symptoms in a 22-item menstrual diary (MD) based on the $\operatorname{Moos}^{23}$ questionnaire, using a 4-point scale $(0$, none; 1 , mild - present but does not interfere with activities; 2, moderate-present and interferes with activities but not disabling; 3 , severe-disabling, unable to function).

\section{Collection and analysis of urine}

Each volunteer was asked to supply three spot urine samples, one before the onset of the study (baseline) and one each while taking the first and second supplements. Urine samples during the supplementation phase were taken after 3 weeks of treatment to ensure a steady flux of $\mathrm{Mg}$. No guidelines were given about the time of day to take urine samples, although volunteers were asked to pack the samples quickly after collection, according to a protocol, and send them immediately by first class mail to the pathology laboratory of the Royal Berkshire Hospital, Reading, where they were stored frozen before analysis.

Urine samples were diluted appropriately and analyzed for creatinine and $\mathrm{Mg}$ by the appropriate Kodak Ektachem Clinical Chemistry Slide (Clinical Products Division, Eastman Kodak Company, Rochester, NY). Estimated 24-hour urinary output of $\mathrm{Mg}$ was calculated without correction for body weight on the assumption that each woman had an output of $8.752 \mathrm{mmol}(990$ $\mathrm{mg}$ ) of creatinine per day. ${ }^{24}$

\section{Statistical analysis}

Table 1 shows how the 27 symptoms recorded in the MHQ were classified for data handling. The classification was a modification of that of Abraham, ${ }^{2}$ using six categories: PMS-A (anxiety), PMS-C (craving), PMS-D (depression), PMS-H (hydration), PMS-O (other), and PMS-T (total). The 22 symptoms of the MD were classified in a similar way (Table 2) for each menstrual cycle. A premenstrual score was calculated for each of these categories by summing the scores within a category for the 7 days before the onset of menses.

Data were collated using DataEase 4.0 (Sapphire DataEase Ltd, Ilford, Essex, U.K.) and analyzed using SAS 6.04 (Statistical Analysis System, SAS, Institute Inc., Cary, NC). Data sets for 1 month of treatment (cycles $1+3$ ) and for 2 
Table 1. Classification of 27 Symptoms of Menstrual Health

Questionnaire SCOREd Retrospectively on 5-Point SCALE

\begin{tabular}{|c|c|c|}
\hline $\begin{array}{l}\text { Symptom } \\
\text { category }\end{array}$ & $\begin{array}{l}\text { Maximum } \\
\text { score }\end{array}$ & Symptoms \\
\hline $\begin{array}{l}\text { PMS-A } \\
\text { (anxiety) }\end{array}$ & 25 & $\begin{array}{l}\text { Difficulty in sleeping, feeling tense, irritable, clumsiness (dropping things), } \\
\text { mood swings }\end{array}$ \\
\hline $\begin{array}{l}\text { PMS-C } \\
\text { (craving) }\end{array}$ & 20 & $\begin{array}{l}\text { Headache, craving for sweet foods, craving for salty food, craving for } \\
\text { other type of food }\end{array}$ \\
\hline $\begin{array}{l}\text { PMS-D } \\
\text { (depression) }\end{array}$ & 30 & $\begin{array}{l}\text { Feeling depressed, getting angry for no reason, easily upset, poor } \\
\text { concentration or memory, feeling bad about myself, violent feelings }\end{array}$ \\
\hline $\begin{array}{l}\text { PMS-H } \\
\text { (hydration) }\end{array}$ & 10 & Bloated feeling in the abdomen, tender breasts \\
\hline $\begin{array}{l}\text { PMS-O } \\
\text { (other) }\end{array}$ & 50 & $\begin{array}{l}\text { Change in bowel habit, period-type pains, backache, passing water } \\
\text { frequently, general aches/ pains, infections (e.g., colds), allergic } \\
\text { reactions, hot flushes or cold sweats, nausea/ sickness, spots (e.g., acne) }\end{array}$ \\
\hline Total & 135 & Sum of the overall symptoms \\
\hline
\end{tabular}

months of treatment (cycles $2+4$ ) were subjected to analysis of variance (ANOVA).

The estimated 24-hour urinary Mg output during $\mathrm{Mg}$ supplementation treatment was compared with output while on placebo treatment, using ANOVA, with baseline values as covariate.

\section{RESULTS}

Of the 54 volunteers who completed the MHQ, 41 completed the MD for cycle 1, 38 for cycle 2, 30 for cycle 3 , and 24 for cycle 4 . In order not to break promised volunteer confidentiality, the reasons for dropout were not followed up. The total numbers of urine specimens received and analyzed were 50 at baseline, 45 during menstrual cycles 1 and 2, and 40 during menstrual cycles 3 and 4 . Thirty-seven volunteers provided all three urine samples required for the study.

\section{Menstrual Health Questionnaire (MHQ)}

Responses to the MHQ were analyzed for the 38 volunteers who provided complete data for menstrual cycle 2 . Only data on these 38 volunteers were included in the ANOVA of the effect of $\mathrm{Mg}$ versus placebo on PMS symptoms. The age range of the 38 subjects was $18-50$ years, but the majority $(71 \%)$ were in the age group $18-25$ years old. The other age range groups were 26-34 years $(7.9 \%), 35-41$ years $(13.2 \%)$, and $41-50$ years $(7.9 \%)$.

The majority $(65.7 \%)$ of volunteers had been between 12 and 13 years of age at menarche, $13.1 \%$ had been $<12$ years old, and $21.1 \%$ had been $>13$ years old. A total of $71.1 \%$ of the volunteers reported regular menstruation, with their periods starting within 2-3 days of the predicted date each month, $26.3 \%$ reported starting within 4-10 days of the predicted date, and only $2.6 \%$ reported their period starting within $>10$ days of

Table 2. Classification of 22 Symptoms in Menstrual Diary Scored Daily on 4-Point Scale

\begin{tabular}{|c|c|c|}
\hline $\begin{array}{l}\text { Symptom } \\
\text { category }\end{array}$ & $\begin{array}{l}\text { Maximum } \\
\text { premenstrual } \\
\text { score }\end{array}$ & Symptoms \\
\hline $\begin{array}{l}\text { PMS-A } \\
\quad \text { (anxiety) }\end{array}$ & 84 & Nervous tension, mood swings, irritability, anxiety \\
\hline $\begin{array}{l}\text { PMS-C } \\
\quad \text { (craving) }\end{array}$ & 126 & $\begin{array}{l}\text { Headache, craving for sweets, increased appetite, heart } \\
\text { pounding, fatigue, dizziness or faintness }\end{array}$ \\
\hline $\begin{array}{l}\text { PMS-D } \\
\quad \text { (depression) }\end{array}$ & 105 & Depression, forgetfulness, crying, confusion, insomnia \\
\hline $\begin{array}{l}\text { PMS-H } \\
\quad \text { (hydration) }\end{array}$ & 84 & $\begin{array}{l}\text { Weight gain, swelling of extremities, breast tenderness, } \\
\text { abdominal bloating }\end{array}$ \\
\hline $\begin{array}{l}\text { PMS-O } \\
\quad \text { (other) }\end{array}$ & 63 & Cramps (low abdominal), backaches, general aches/pains \\
\hline Total & 462 & Sum of the overall symptoms \\
\hline
\end{tabular}


the predicted date each month. Menstruation lasting 5 days was reported by $57.9 \%$ of the subjects, $<5$ days by $13.2 \%$, and $>5$ days by $28.9 \%$ of the subjects. Menstruation was described as medium blood loss by $70.3 \%$, light blood loss by $13.5 \%$, and heavy blood loss by $16.2 \%$.

With reference to parity, 7 of the 38 volunteers (18.4\%) had given birth to one or more children. OC were taken by $31.6 \%$ of the 38 women, of whom $50 \%$ were in their first year of OC treatment, and $33.3 \%$ had been taking OC for the last 2-3 years. Within the group not taking OC $(n=$ 26), 2 subjects reported that they had stopped taking OC less than 1 year ago, and 6 subjects reported that they had stopped taking OC longer than 1 year ago.

When asked if they felt that they were currently subject to stress, $81.1 \%$ reported some stress, $5.4 \%$ reported a great deal of stress, and $13.5 \%$ reported no stress. Regarding their last menstrual period (on which they were also required to made a retrospective assessment score of the severity of PMS suffered, using a 27 PMS symptom classification), 59.5\% selected the alternative "as bad as usual," $13.5 \%$ selected "better than usual," $10.8 \%$ selected "worse than usual," and 16.2\% selected the alternative "no unpleasant changes."

Of the 38 women, 26 reported suffering from PMS for 1-5 years, 6 for 6-10 years, and 4 for $>10$ years ( 2 did not report). When asked if they have found any cure for PMS, $77.8 \%$ had not, but $22.2 \%$ had found a variety of remedies, including exercise, relaxation, and taking evening primrose oil.

The second part (Part II) of the MHQ yielded data on the symptom scores in the premenstrual and postmenstrual phases of the volunteers' last cycle. Mean premenstrual scores and the difference between mean premenstrual and postmen- strual scores for each of the PMS categories are shown in Table 3.

\section{Premenstrual symptoms}

The mean PMS scores for Mg or placebo supplementation for pooled arms of the study at 1 and 2 months are shown in Table 4 . The percentage of maximum scores for 1 and 2 months of supplementation was low, varying between 5.8 and 16.5 for all symptoms, indicating that most of the volunteers were suffering only mild symptoms during the 7 days included in the score. Indeed, category PMS-O, comprising symptoms not necessarily associated with PMS, was the most prevalent category $(14 \%$ of maximum score). This was followed by PMS-A, PMS-C, PMS-H, and PMS-D $(12 \%, 8.9 \%, 7.4 \%$, and $6.9 \%$ of maximum score, respectively).

ANOVA showed no significant difference in any of the symptom categories after 1 month of supplementation. However, after 2 months of supplementation, a significant difference ( $p=$ 0.009 ) was found between mean premenstrual scores for $\mathrm{Mg}$ (4.96) and placebo (7.19) supplementation for PMS-H (Table 4), although 2 months of supplementation showed no significant effect of the different treatments for any other symptom category, including PMS-T scores, even though scores were all lower when the subjects were taking $\mathrm{Mg}$. Tests for the carryover effect of $\mathrm{Mg}$ supplementation in the first arm of the study into the placebo period of the second arm of the study were nonsignificant.

\section{Urinary magnesium output}

A total of 37 subjects provided all three urine samples required in the study, and these were in-

Table 3. Premenstrual Symptom Categories from the Menstrual Health Questionnaire: Comparison of Mean Premenstrual and Postmenstrual Scores for 38 Women

\begin{tabular}{|c|c|c|c|}
\hline $\begin{array}{l}\text { Symptom } \\
\text { category }\end{array}$ & $\begin{array}{l}\text { Premenstrual } \\
\text { scores }^{\mathrm{a}}\end{array}$ & $\begin{array}{l}\text { Postmenstrual } \\
\text { scores }^{\mathrm{a}}\end{array}$ & $\begin{array}{c}\text { Difference between } \\
\text { premenstrual and } \\
\text { postmenstrual scores }\end{array}$ \\
\hline PMS-A (anxiety) & $19.11 \pm 5.38$ & $3.79 \pm 4.10$ & $15.32 \pm 6.63$ \\
\hline PMS-C (craving) & $5.50 \pm 3.11$ & $1.53 \pm 1.81$ & $3.97 \pm 3.31$ \\
\hline PMS-D (depression) & $9.84 \pm 3.81$ & $2.02 \pm 2.24$ & $7.82 \pm 4.18$ \\
\hline PMS-H (hydration & $4.47 \pm 2.45$ & $0.68 \pm 0.96$ & $3.79 \pm 2.42$ \\
\hline PMS-O (other) & $12.95 \pm 6.84$ & $3.37 \pm 3.91$ & $9.58 \pm 6.36$ \\
\hline Total & $51.87 \pm 14.77$ & $11.38 \pm 11.52$ & $40.47 \pm 16.90$ \\
\hline
\end{tabular}

aMean \pm SD. 
Table 4. Premenstrual Symptom Scores from Menstrual Diaries for Women Receiving Daily Supplement of Mg or Placebo

\begin{tabular}{|c|c|c|c|c|c|}
\hline \multirow{2}{*}{$\begin{array}{l}\text { Months of } \\
\text { supplementation }\end{array}$} & \multirow{2}{*}{$\begin{array}{l}\text { Symptom } \\
\text { category }\end{array}$} & \multicolumn{2}{|c|}{$M g$} & \multicolumn{2}{|c|}{ Placebo } \\
\hline & & $\mathrm{n}$ & Score ${ }^{\mathbf{a}}$ & $\mathrm{n}$ & Score ${ }^{\mathrm{a}}$ \\
\hline \multirow[t]{6}{*}{1} & PMS-A & \multirow[t]{6}{*}{35} & $10.74 \pm 7.81$ & \multirow[t]{6}{*}{36} & $10.08 \pm 7.47$ \\
\hline & PMS-C & & $10.77 \pm 7.19$ & & $13.19 \pm 9.45$ \\
\hline & PMS-D & & $7.89 \pm 6.47$ & & $8.28 \pm 7.70$ \\
\hline & PMS-H & & $6.09 \pm 3.85$ & & $6.56 \pm 4.88$ \\
\hline & PMS-O & & $8.80 \pm 7.27$ & & $9.97 \pm 9.74$ \\
\hline & Total & & $44.29 \pm 26.12$ & & $48.05 \pm 34.15$ \\
\hline \multirow[t]{6}{*}{2} & PMS-A & \multirow[t]{6}{*}{30} & $8.30 \pm 8.11$ & \multirow[t]{6}{*}{32} & $12.43 \pm 11.93$ \\
\hline & PMS-C & & $9.90 \pm 8.46$ & & $11.46 \pm 7.21$ \\
\hline & PMS-D & & $6.13 \pm 4.43$ & & $7.34 \pm 7.08$ \\
\hline & PMS-H* & & $4.96 \pm 3.09$ & & $7.19 \pm 5.08$ \\
\hline & PMS-O & & $7.53 \pm 8.21$ & & $10.40 \pm 10.49$ \\
\hline & Total & & $36.80 \pm 23.88$ & & $48.75 \pm 35.25$ \\
\hline
\end{tabular}

aMean \pm SD.

*Significantly different from placebo $(p=0.009)$.

cluded in the ANOVA. The estimated 24-hour urinary $\mathrm{Mg}$ output of these samples is shown as distribution plots in Figure 1 and as mean data for the 37 subjects at baseline and during supplementation in Table 5. ANOVA, using baseline data (mean of $71.6 \mathrm{mg} /$ day) as covariate, showed that mean estimated 24-hour urinary $\mathrm{Mg}$ output significantly increased $(p=0.013)$ when subjects were taking $\mathrm{Mg}$ supplement (mean of 100.8 $\mathrm{mg} /$ day) compared with placebo (mean of 74.1 $\mathrm{mg} /$ day).

\section{DISCUSSION}

The majority of the volunteers $(72 \%)$ were university students, aged $18-25$ years old, who suffered only mild premenstrual symptoms that were not severe enough to be classified as PMS. In this age group, the incidence of premenstrual symptomatology tends to be lower than in older age groups.,25,26 Stressful life events have been postulated to exacerbate the symptoms. Indeed, stress load must be a factor to consider when recruiting volunteers. ${ }^{7,27}$ However, only $5.4 \%$ of our subjects recorded undergoing a great deal of stress at the time the MHQ was completed, so stress may not have been a major factor for women in this study.

OC users were not excluded from this study. Although controversial, clinical experience indicates that OC may help to relieve premenstrual symptoms at least in the short term, and, thus, OC users are less likely to suffer. Chronic use of
OC, however, has been related to the development of depression and other PMS symptoms, such as breast tenderness due to estrogen dominance. ${ }^{28}$ In the present study, most volunteers using OC $(n=12)$ had been taking them for less than a year, and in view of this fact and the small numbers involved, separate analysis of this subset was not attempted.

Compared with maximum scores, the MHQ symptom scores showed PMS-A as being most prevalent among the 38 volunteers (76\%). PMS-H was the next most prevalent symptom category ( $48 \%$ of maximum score), with the other PMS categories ranging from $24 \%$ to $38 \%$ of the maximum scores. The finding that PMS-A was the predominant category coincides with Abra-

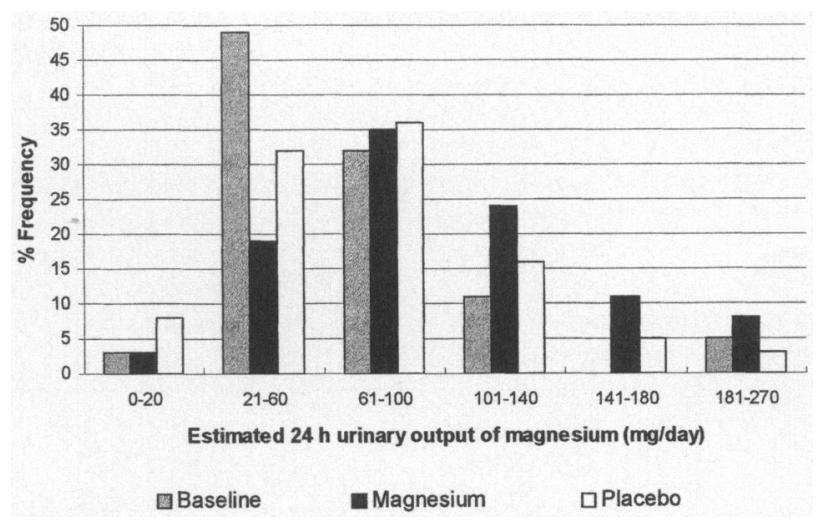

FIG. 1. Distribution of estimated 24-hour urinary output of $\mathrm{Mg}$ (mg/day) of 37 women at baseline (no supplementation) and during supplementation with 200 $\mathrm{mg} /$ day $\mathrm{Mg}$ or placebo. 
Table 5. Estimated 24-Hour Urinary Mg Output at Baseline and During Second Cycle of Supplementation with Mg or Placebo $(n=37)$

\begin{tabular}{lcc}
\hline Urine samples & $\begin{array}{c}\text { Means } \\
(m g / \text { day })\end{array}$ & $S D$ \\
\hline Baseline & 71.6 & 45.4 \\
Magnesium & $100.8^{*}$ & 51.1 \\
Placebo & 74.1 & 42.3 \\
\hline
\end{tabular}

${ }^{*}$ Significantly different from placebo $(p=0.013)$.

ham and Rumley's clinical and experimental findings. ${ }^{29}$

The premenstrual scores and the difference between premenstrual and postmenstrual scores for each of the symptom categories from the MHQ (Table 3) show little variation, indicating that the symptoms suffered in the postmenstrual phase were slight. Thus, those recorded in the premenstrual phase can truly be regarded as part of the premenstrual syndrome. These results concur with a proposed definition of premenstrual syndrome by $\mathrm{O}^{\prime} \mathrm{Brien}^{30}$ that symptoms in the luteal phase of the cycle are relieved by the onset of menstruation or during menstruation, with a symptom-free follicular phase postmenstruation.

Premenstrual scores from the MD for the various symptom categories showed $\mathrm{Mg}$ supplementation ( $200 \mathrm{mg} /$ day) to be helpful ( $p=0.009)$ in alleviating symptoms of PMS-H compared with placebo after 2 months but not after 1 month of treatment (Table 4). No differences between $\mathrm{Mg}$ and placebo treatment were observed for any other premenstrual score categories, although all scores were lower under $\mathrm{Mg}$ supplementation than placebo after 2 months' supplementation. As baseline MD were not requested in this study, the extent of the placebo effect was not determined, although other studies on intervention treatment for PMS have shown that the placebo effect is substantial. ${ }^{31,32}$

Although all symptom categories showed reduction of symptoms after 2 months of $\mathrm{Mg}$ supplementation compared with placebo, confirming the findings of Facchinetti et al., ${ }^{3}$ the categories showing a statistically significant change were different in the two studies. Facchinetti et al. ${ }^{3}$ showed a significant difference in negative affect (equivalent to the category of PMS-D in this report) and PMS-T symptoms but not of symptoms of PMS-H. Differences in the study design may be partly responsible for this. Facchinetti et al. ${ }^{3}$ administered the $\mathrm{Mg}$ supplement from day 15 to the end of the cycle, not continuously, and the dose was higher ( $360 \mathrm{mg} \mathrm{Mg} /$ day) and administered in three divided doses. Also, the group of women randomized to take an $\mathrm{Mg}$ supplement for 2 months was continued on $\mathrm{Mg}$ for a further 2 months. At the end of that time, the researchers were able to show a significant effect of $\mathrm{Mg}$ supplementation compared with 2 months of $\mathrm{Mg}$ supplementation in symptoms of PMS-H.

It is not clear why PMS-H should be the category to show response in our study after only 2 months of $\mathrm{Mg}$ supplementation, although the state of $\mathrm{Mg}$ repletion of the subjects may have been different. $\mathrm{Mg}$ repletion is best assessed through urinary $\mathrm{Mg}$ output, which was not measured by Facchinetti et al. ${ }^{3}$ Our results showed mean estimated $\mathrm{Mg}$ output to be at the lower end of the normal range.

The lack of significant effects of treatment in the first month of supplementation (Table 4) in our study may have been due to the low dose used for $\mathrm{Mg}$ supplementation (200 mg/day), which may have required several weeks to normalize low $\mathrm{Mg}$ status. This likelihood raises the question of a carryover effect. No washout period was allowed between treatments in this study, so it is possible that symptoms experienced among the placebo treatment group in the second arm of the study may have been influenced even by the nonsignificant effect of carryover of $\mathrm{Mg}$ supplementation from the first arm of the study. Hence, if a washout period had been planned as part of the protocol, it is likely that further significance in the differences between the groups would have been found.

The mean value of $71.6 \mathrm{mg} /$ day (Table 5) for the estimated 24-hour urinary output of $\mathrm{Mg}$ at baseline for the 37 women completing the urine collections was below the normal range of $72.9-109.4 \mathrm{mg} / 24$ hours. ${ }^{33} \mathrm{~A}$ low output of $\mathrm{Mg}$ is a reflection of a low dietary intake, which is common among women in Britain. Compared with the RNI for $\mathrm{Mg}$ for adult women of $270 \mathrm{mg} /$ day $_{,}{ }^{12}$ Gregory et al. ${ }^{11}$ showed, from a weighed dietary survey of over 1000 women, that the mean intake of $\mathrm{Mg}$ for all ages was $237 \mathrm{mg} /$ day. The intake was even lower in 16-24-year-old women (mean of $215 \mathrm{mg} /$ day), and for women with the lowest intake (2.5\% of all women surveyed), it was less than $105 \mathrm{mg} /$ day.

Support for these findings of low $\mathrm{Mg}$ intake among British women also comes from the British National Food Survey, ${ }^{34}$ in which the mean daily 
$\mathrm{Mg}$ intake estimated for women was only $84 \%$ of the RNI. Volunteers in the present study were mostly young female students, who may not have the time or the inclination to include sufficient whole grain cereals, nuts, beans, and dark green leafy vegetables in their diets to obtain an adequate intake of $\mathrm{Mg}$.

The mean estimated 24-hour urinary output of $\mathrm{Mg}$ for 37 subjects while on placebo treatment was not significantly different from baseline values (Table 5), indicating that placebo had no influence on $\mathrm{Mg}$ output, as might be expected. When the subjects were supplemented with $\mathrm{Mg}$, however, there was a significant increase in $\mathrm{Mg}$ output in the urine $(p=0.013)$. Although significant, the increased value (mean $100.8 \mathrm{mg} /$ day) was still within the normal range, although at the higher end of the range. Although the extent of absorption of $\mathrm{Mg}$ from $\mathrm{MgO}$ by human subjects is unknown, this form of the mineral has been favored for use in dietary supplements because of its low bulk. This study shows that a supplement providing $200 \mathrm{mg} /$ day of elemental $\mathrm{Mg}$ as $\mathrm{MgO}$ can increase urinary $\mathrm{Mg}$ output, indicating its bioavailability.

\section{CONCLUSIONS}

A low-dose daily supplement of $200 \mathrm{mg}$ of $\mathrm{MgO}$ significantly reduced mild premenstrual symptoms of fluid retention (PMS-H) in women suffering premenstrual symptoms in the second cycle of supplementation, but not during the first cycle, compared with placebo. Compliance to treatment was confirmed by a significant increase in urinary $\mathrm{Mg}$ excretion while women were supplemented with $\mathrm{MgO}$. Further studies are warranted on $\mathrm{Mg}$ supplementation of subjects with more severe symptoms, using higher doses of $\mathrm{Mg}$, and making adequate allowance for a carryover effect.

\section{ACKNOWLEDGMENTS}

We are grateful to the volunteers who took part in the study, the CAPES Foundation, Brazil, and ISFE-International Foundation for Nutritional Research, Switzerland, for funding to M.C. De Souza, and Lamberts Healthcare Ltd, who donated the supplements. Thanks are also due to
Ms. C. Cockcroft, Ms. K. Graham, Ms. R. Kemble, and Ms. A. Povall for liaising with volunteers.

\section{REFERENCES}

1. Reid RL, Yen SSC. Premenstrual syndrome. Am J Obstet Gynecol 1981;1:85.

2. Abraham GE. Nutritional factors in the etiology of the PMS. J Reprod Med 1983;28:446.

3. Facchinetti F, Borella P, Sances G, Fioroni L, Nappi RE. Oral magnesium successfully relieves premenstrual mood changes. Am Coll Obstet Gynecol 1991; 78:177.

4. Dalton K. Premenstrual syndrome. London: William Heinemann Medical Books Limited, 1964.

5. Johnson SR, McChesney C, Bean JA. Epidemiology of premenstrual symptoms in a nonclinical sample. I. Prevalence, natural history and help-seeking behavior. J Reprod Med 1988;33:340.

6. Hargrove JT, Abraham GE. Incidence of premenstrual tension in a gynecologic clinic. J Reprod Med 1982; 27:721.

7. Warner P, Bancroft J. Factors related to self-reporting of the premenstrual syndrome. Br J Psychiatry 1990; 157:249.

8. Stewart A. A rational approach to treating premenstrual syndrome. P.O. Box 268, Hove, East Sussex, BN13 1RN, U.K: Women's Nutritional Advisory Service Publication, 1989.

9. Schagen Van Leeuwen JH, Te Velde ER, Koppeschaar HPF, et al. Review: Is premenstrual syndrome an endocrine disorder? J Psychosom Obstet Gynecol 1993; $14: 91$.

10. Geoi GS, Ralston JI, Abraham Ge. Dietary patterns of patients with premenstrual tension. J Appl Nutr 1982;34:4.

11. Gregory J, Foster K, Tyler H, Wiseman M. The Dietary and Nutritional Survey of British Adults. London: HMSO, 1990.

12. Department of Health. Dietary Reference Values for Food Energy and Nutrients for the United Kingdom. London: HMSO, 1991.

13. Sherwood RA, Rocks BF, Stewart A, Saxton RS. Magnesium and the premenstrual syndrome. Ann Clin Biochem 1986;23:667.

14. Abraham GE, Lubran MM. Serum and red cell magnesium levels in patients with premenstrual tension. Am J Clin Nutr 1981;34:2364.

15. Rosenstein DL, Elin RJ, Hosseini JM, Grover G, Rubinow DR. Magnesium measures across the menstrual cycle in premenstrual syndrome. Biol Psychiatry 1994;35:557.

16. Posaci C, Erten O, Uren A, Acar B. Plasma copper, zinc and magnesium levels in patients with premenstrual tension syndrome. Acta Obstet Gynecol Scand 1994;73:452.

17. Hunt SM, Groff JL. Advanced nutrition and human 
metabolism. New York: West Publishing Company, 1990.

18. Shibamoto T, Bjeldanes LF. Introduction to food toxicology. New York: Academic Press, 1993.

19. Kemp PA, Gardiner SM, March JE, Bennett T, Rubin PC. Effects of NG-nitro-L-arginine methyl ester on regional haemodynamic responses to $\mathrm{MgSO}_{4}$ in conscious rats. Br J Pharmacol 1994;111:325.

20. Nadler JL, Goodson S, Rude RK. Evidence that prostacyclin mediates the vascular action of magnesium in humans. Hypertension 1987;9:379.

21. Mauskop A, Altura BM. Role of magnesium in the pathogenesis and treatment of migraines. Clin Neurosci 1998;5:24.

22. Facchinetti F, Sances G, Borella P, Genazzani AR, Nappi RE. Magnesium prophylaxis of menstrual migraine effects on intracellular magnesium. Headache 1991;31:298.

23. Moos RH. The development of a Menstrual Distress Questionnaire. Psychiat Med 1968;30:853.

24. Claudio VS, Lagua RT. Nutrition and diet therapy dictionary, 3rd ed. New York: Van Nostrand Reinhold, 1991.

25. Hargrove JT, Abraham GE. Effect of vitamin $B_{6}$ on infertility in women with the premenstrual tension syndrome. Infertility 1979;2:315.

26. Dinan TG, O'Keane V. The premenstrual syndrome: A psychoneuroendocrine perspective. Bailliere's Clin Endocrinol Metab 1991;5:145.

27. Mortola JF. Assessment and management of premenstrual syndrome. Curr Opin Obstet Gynecol 1992;4: 877.
28. Bancroft J. The premenstrual syndrome-A reappraisal of the concept and the evidence. Psychol Med J 1993;5:1.

29. Abraham GE, Rumley RE. Role of nutrition in managing the premenstrual tension syndromes. J Reprod Med 1987;32:405.

30. O'Brien PM. Premenstrual syndrome. London: Blackwell Scientific, 1987.

31. Doll H, Brown S, Thurston A, Vessey M. Pyridoxine (vitamin $B_{6}$ ) and the premenstrual syndrome: A randomized crossover trial. J R Coll Gen Pract 1989;39: 364.

32. London RS, Bradley MS, Chiamori NY. Effect of a nutritional supplement on premenstrual symptomatology in women with premenstrual syndrome: A double-blind longitudinal study. J Am Coll Nutr 1991;10: 494.

33. Churchill's illustrated medical dictionary. Edinburgh: Churchill Livingstone, 1989.

34. National Food Survey Committee. Household food composition and expenditure 1990 with a study of trends over the period 1940-1990. London: HMSO, 1991.

Address reprint requests to: Dr. Ann Walker

Hugh Sinclair Unit of Human Nutrition Department of Food Science and Technology

The University of Reading Reading RG6 6AP United Kingdom 